\title{
Particularidades do Português Tocantinense: resultados do Atlas Linguístico Topodinâmico e Topoestático do Estado do Tocantins (ALiTTETO)
}

\author{
Characteristics of the Portuguese language in the state of Tocantins, Brazil-results \\ of Tocantins's topodynamic and topoestatic linguistic atlas (ALiTTETO)
}

Greize Alves da SILVA*

Universidade Federal do Tocantins (UFT)

\begin{abstract}
RESUMO: O atual Tocantins, desmembrado do espaço goiano em 1988, apresenta características migratórias intensas, sobretudo de populações procedentes das regiões Norte e Nordeste, o que se traduz em ações centrípetas e centrífugas relacionadas às formas dialetais de informantes locais e migrantes. Em razão desse movimento de falantes plurivarietais, realizamos o "Atlas Linguístico Topodinâmico e Topoestático do Estado do Tocantins" ALiTTETO (2018), defendido como tese de doutorado na Universidade Estadual de Londrina. O trabalho, lato sensu, foi composto por inquéritos realizados em 12 localidades, junto a 96 informantes estratificados por idade, sexo e mobilidade (migrante e não migrante). Neste recorte, fornecemos resultados nos níveis fonético-fonológico, mais precisamente na variação do rótico em coda medial, que atrela o Tocantins a uma norma fonética presente nas regiões Norte e Nordeste brasileira; e no viés lexical, com a apresentação das variantes para libélula/cambito/cavalo/cavalinho (de/do capeta, cão, judeu), que demonstra a formação de área dialetal nas proximidades com o espaço intitulado como Falar Baiano.
\end{abstract}

PALAVRAS-CHAVE: ALiTTETO; Dialetologia Pluridimensional; português tocantinense.

ABSTRACT: The state of Tocantins, separated from the Goiás state in 1988, is characterized by heavy migration, especially populations from the northern and northeastern regions of Brazil, which amounts to centripetal and centrifuge activities related to dialectal forms of local and migrant informants. Due to plurivariegate speakers, the Tocantins's Topodynamic and Topostatic Linguistic Atlas - ALiTTETO (2018) was prepared and exposed in a viva voce doctoral thesis at the State University of Londrina, Londrina, Brazil. The task comprised surveys in 12 places and 96 informants, stratified by age, gender and mobility (migrant or nonmigrant). Results at phonetic and phonological levels were provided, specifically within the rhotic variation in medial coda binding the state of Tocantins with the phonetic norm current in the northern and northeastern regions of Brazil. Further, within the lexical stance, the case of variants for libélula/cambito/cavalo/cavalinho (de/do capeta, cão, judeu) demonstrates the formation of dialectal area in the neighborhood of space of Bahia speech.

KEYWORDS: ALiTTETO; Pluridimensional dialectology; portuguese of the state of Tocantins.

\footnotetext{
* Doutora em Estudos da Linguagem pela UEL. Professora no Programa de Pós-graduação em Letras (PPG-LETRAS/UFT). E-mail: greize_silva@yahoo.com.br
}

Revista Moara, n. 55, jan-jul 2020 ISSN: 0104-0944

Recebido em 07/11/2019

Avaliado em 29/07/2020 


\section{Introdução}

Nas últimas décadas, nós, dialetólogos, temos presenciado aumento substancial de pesquisas que visam a descrição de nuances variacionistas em diferentes realidades, seja em seu caráter mais diatópico (Dialetologia Areal), seja por meio da modalidade diatópica-social (Dialetologia Pluridimensional), o que tem trazido importantes contribuições ao estado da arte e, consequentemente, o aumento significativo de atlas linguísticos em diferentes perspectivas.

O plano da Dialetologia Pluridimensional e Relacional, que alia os preceitos da diatópia às variáveis inter e intraindividuais, tem fornecido subsídios no aporte teóricometodológico para a feitura de atlas em áreas de instabilidade migratória, sobretudo em realidades que coexistem falantes plurivarietais, onde autóctones e migrantes convivem e realizam trocas linguísticas (ALTENHOFEN, 2013, p. 36). Essa realidade é evidenciada no Tocantins, espaço anteriormente pertencente ao estado de Goiás.

Em termos históricos, a presença de diferentes núcleos populacionais no espaço mais ao norte do estado goiano foi constante, sobretudo a de grupos nordestinos e nortistas, que comumente se fixavam às margens direita do rio Tocantins. A partir da década de 1950, dois marcos sinalizam a chegada de outras levas migratórias: o primeiro decorre do início da construção do Rodovia Belém-Brasília - BR 153, que trouxe outros tipos de migrantes: os procedentes do Centro-Oeste, do Sudeste e do Sul. O segundo marco, em 1989, decorre do início da construção da capital Palmas, trazendo migrantes procedentes das mais diversas origens. Segundo estimativas censitárias, aproximadamente $40 \%$ da população do Tocantins é migrante, principalmente goianos e maranhenses (CUNHA; BAENINGER, 2000).

Dado o caráter multivarietal do então criado estado do Tocantins e da coexistência entre informantes de diferentes modalidades dialetais, empreendemos em 2014 o objetivo geral de elaborar o "Atlas Linguístico Topodinâmico e Topoestático do Estado do Tocantins", vinculado ao Programa de Doutorado em Estudos da Linguagem, da Universidade Estadual de Londrina. Mais especificamente, pretendeu-se descrever a realidade dialetal tocantinense, com enfoque nas dimensões interindividuais, com as variáveis diassexuais, diageracionais, diatópico-topoestáticas e diatópico-cinética, consideradas na perspectiva da Dialetologia Pluridimensional (SILVA, 2018).

Revista Moara, n. 55, jan-jul 2020 ISSN: 0104-0944

Recebido em 07/11/2019

Avaliado em 29/07/2020 
Para este artigo, elencamos duas análises realizadas no corpus da tese: uma fonética, especificamente sobre os róticos em coda medial, e outra de caráter lexical, abrangendo as designações para cambito/libélula/ cavalo/cavalinho (de/do capeta, cão, judeu) que demonstram a formação de área dialetal, intitulada "Tocantins Antigo" (SILVA, 2018).

\section{Aporte teórico do ALiTTETO: a pluridimensionalidade dialetal}

A Dialetologia, em essência, nasceu sob uma perspectiva diatópica, considerando o informante ideal para o tipo de inquérito o homem, morador da zona rural, com pouca mobilidade demográfica. No entanto, em termos brasileiros, cuja população considerada rural está cada mais menor, esse perfil mais estático, pretérito pela Dialetologia, constitui-se uma exceção, dado o acesso a meios de comunicação em massa, rodovias etc. (SILVA; BORGES, 2019). Assim, buscar o falante totalmente estático à sua localidade de nascimento é negar a própria realidade histórica e social do país.

Outro importante marco para a mudança de paradigmas da Dialetologia Areal (diatópica) surgiu com as contribuições de Labov, na década de 60. O autor demonstrou que o comportamento linguístico do falante não pode se desvencilhar de fatores como idade, sexo, escolaridade e profissão, por exemplo, elementos essenciais para se descrever a língua em contexto real de uso (LABOV, 2008 [1972]). Desde então, esses subsídios labovianos começaram a fazer parte do arcabouço teórico da Dialetologia, sobretudo nas últimas décadas ${ }^{1}$.

Assim, a Dialetologia, puramente espacial, cede espaço à novas incorporações teórico-metodológicas da Sociolinguística, uma vez que há "a consciência de que é necessário agregar ao estudo da dimensão areal o estudo de outros tipos de variação"2 (THUN, 1998, p. 702 [tradução nossa]), acompanhando uma nova dinâmica social, cujo falante é móvel dentro de seu espaço social.

\footnotetext{
${ }^{1}$ Como exemplo brasileiro temos o Atlas Linguístico do Brasil, que controla variáveis como idade, sexo e nível de escolarização.

${ }^{2}$ No original: "la consciência de que es muy necessário agregar al estudio de ladimensión areal el de otros tipos de variación” (THUN, 1998, p. 702).
} 
Por conta dessa consciência, em que se destaca também a não fixidez do informante à sua localidade, a Dialetologia Dialetologia Pluridimensional e Relacional entende que "a superfície bidimensional horizontal da Dialetologia e o eixo vertical da Sociolinguística formam o espaço variacional tridimensional da Dialetologia Pluridimensional e Relacional ${ }^{3 "}$ (THUN, 1998, p. 704 [tradução nossa]). Nessa perspectiva de abordagem da variação linguística, várias associações podem ser realizadas em termos sociodialetais, com o intuito de se formar uma superfície tridimensional variacionista, ampliando o perfil do informante. Para Thun (1998):

[...] o espaço variacional da Dialetologia Pluridimensional não compreende somente os dialetos "puros" preferidos pela Dialetologia tradicional ou os socioletos da Sociolinguística. São de igual interesse as variedades mistas, os fenômenos de contato linguístico entre línguas contíguas ou superpostas de minorias e maiorias, formas regionais, a variação diafásica (ou estilística), o comportamento linguístico dos grupos topodinâmicos (demograficamente móveis) contrastando com o dos grupos topoestáticos (com pouca mobilidade do espaço), a atitude metalinguística dos falantes comparada com seu comportamento linguístico, e outros parâmetros mais ${ }^{4}$ (THUN, 1998, p. 706 [tradução nossa]).

$\mathrm{Ou}$ seja, ao unir as duas disciplinas, Dialetologia e Sociolinguística, por excelência variacionistas, tem-se as chamadas dimensões, que podem ser separadas em dois grupos: (i) interindividuais, englobando as perspectivas diatópica, diastrática, diageracional, diassexual e diatópica-cinética e (ii) intraindividuais, com os parâmetros diafásico, contatual/dialingual e diarreferencial (FIGUEIREDO, 2014, p. 45).

A interpretação interindividual diz respeito ao indivíduo em situação de contato com o seu meio social, no qual são considerados fatores como idade, profissão e categoria social do falante, por exemplo. Em relação a dimensão diatópico-cinética, ela alude a um modelo presente no campo da Física sob a ação dos movimentos dos corpos. Em termos dialetológicos, busca analisar a dinâmica dialetal dos grupos migrantes dentro de uma localidade, em contraste com os grupos autóctones, uma vez que a

\footnotetext{
${ }^{3}$ No original: "La superficie bidimensional horizontal de la Dialetología y el eje vertical de la Sociolingüística forman juntos el espacio variacional tridimensional de la Dialetología Pluridimensional y relacional" (THUN, 1998, p. 704).

${ }^{4}$ No original: "O espacio variacional de la Dialectología Pluridimensional no compreende solamente los dialectos "puros" preferidos por la Dialectología tradicional o los sociolectos de la Sociolingüística. Son de igual interés las variedades mixtas, los fenómenos de contacto lingüístico entre lenguas contiguas o superpuestas de minorias y de mayorías, formas regionales, la variación diafásica (o estilística), el comportamiento lingüístico de los topodinámicos (demográficamente móviles) contrastando con el de los grupos topoestáticos (poco móviles en el espacio), la actitud metalingüística de los hablantes comparada con su comportamiento lingüístico, y otros parámetros más.” (THUN, 1998, p. 706).
} 
convivência entre os dois tipos de informantes gera, por vezes, situação de instabilidade linguística; é nessa premissa que o ALiTTETO foi realizado.

Para Altenhofen e Thun, falantes mais estáticos à localidade demonstram atitude linguística mais convergentes com seu espaço habitual, porquanto, um migrante pode seguir um caminho mais centrífugo, evitando adapta-se ao falar local e mantendo seu dialeto da comunidade de origem, como forma de reafirmação dialetal (ALTENHOFEN; THUN, 2016, p. 376).

Para Silva (2018), a ação centrífuga descrita pelos autores não se evidenciou no corpus do ALiTTETO (2018), possivelmente em razão de algumas condições: i) maior aceitabilidade dos grupos locais em receber os migrantes não-tocantinenses; ii) necessidade do alóctone em ser aceito por essa nova comunidade falante, ou iii) significativa melhora econômica desse migrante no Tocantins, o que o leva possuir crenças positivas relacionadas ao novo espaço. Nesse caso, as trocas dialetais realizadas no Tocantins encontram-se interligadas à fatores de ordem histórica e social, cujo contato com o migrante sempre foi uma constante para as populações mais locais.

\section{Bases metodológicas utilizadas no ALiTTETO}

A seleção das 12 localidades deu-se a partir de dois critérios: o histórico-cultural e o político-geográfico. Segundo o primeiro, selecionamos as cidades que outrora funcionaram como arraiais de mineração, entrepostos comerciais, ou seja, representam a formação do espaço norte do estado de Goiás. De acordo com a segundo critério, consideramos as cidades com maior potencial econômico e com substancial contingente populacional, algumas fronteiriças com unidades federativas limítrofes ao Tocantins ${ }^{5}$. Assim, as localidades que integram a rede de pontos do ALiTTETO são estas: 01 Araguatins; 02 -Tocantinópolis; 03 - Araguaína; 04 - Araguacema; 05 - Pedro Afonso; 06 - Palmas; 07 - Porto Nacional; 08 - Gurupi; 09 - Mateiros; 10 Formoso do Araguaia; 11 - Natividade e 12 - Paranã.

Os inquéritos foram concluídos em, aproximadamente, oito meses e contaram com a colaboração efetiva, além da autora do Atlas, dos seguintes inquiridores: Bruna Lorraynne Dias Menezes, Tassita Kamassagre Ferreira Alves e Kleiton Araújo, na

\footnotetext{
${ }^{5}$ Os estados fronteiriços ao Tocantins são: Maranhão, Piauí, Bahia, Pará, Mato Grosso e Goiás. 
época, ainda alunos de graduação e participantes de iniciação científica da Universidade Federal do Tocantins, campus de Porto Nacional.

Como o ALiTTETO foi pensado dentro de um modelo Pluridimensional, que deveria abarcar, além dos falantes estáticos às localidades de pesquisa, também os topodinâmicos, informantes procedentes de deslocamentos ou migrações estaduais, definimos o número de oito por localidade, selecionados por idade, sexo e tipo de mobilidade, somando, ao todo 96 informantes, conforme quadro 1:

Quadro 1: Perfil dos informantes do ALiTTETO

\begin{tabular}{|c|c|c|c|}
\hline $\mathbf{N .}^{\mathbf{0}}$ & Sexo & Idade & Mobilidade \\
\hline $\mathbf{1}$ & Homem & de 18 a 30 & Topoestático \\
\hline $\mathbf{2}$ & Mulher & de 18 a 30 & Topoestático \\
\hline $\mathbf{3}$ & Homem & de 50 a 65 & Topoestático \\
\hline $\mathbf{4}$ & Mulher 50 a 65 & Topoestático \\
\hline $\mathbf{5}$ & Homem & de 18 a 30 & Topodinâmico \\
\hline $\mathbf{6}$ & Mulher & de 18 a 30 & Topodinâmico \\
\hline $\mathbf{7}$ & Homem & de 50 a 65 & Topodinâmico \\
\hline $\mathbf{8}$ & Mulher & de 50 a 65 & Topodinâmico \\
\hline
\end{tabular}

Fonte: ALiTTETO (SILVA, 2018).

A sequência numérica de 1 a 4 representa os informantes estáticos às localidades (topoestáticos), enquanto a de 5 a 8 é relativa aos procedentes de deslocamentos internos ou migrações (topodinâmicos). Os números ímpares representam os homens; os pares as mulheres. Sobre a faixa etária dos entrevistados, trabalhamos com o mesmo perfil etário do Atlas Linguístico do Brasil (ALiB): 18 a 30 anos, de 50 a 65 anos, para fins de comparabilidade posterior.

O instrumento de coleta aplicado baseou-se no Questionário do ALiB (2001), com adaptações relacionadas principalmente ao léxico regional, totalizando 340 perguntas distribuídas em subcampos: fonético-fonológico, semântico-lexical, morfossintático, relatos livres e crenças e atitudes linguísticas.

Dado o caráter temporal para a feitura da tese, trabalhamos apenas com partes do questionário fonético-fonológico e do semântico-lexical. Na fonética foram objetos de 
análise: a abertura das vogais médias em contexto pretônico, com o /R/ em coda silábica interna e externa e com o /S/ pós-vocálico em coda medial.

No nível lexical, analisamos 17 questões oriundas dos campos semânticos: Atividades Agropastoris, Corpo Humano, Fauna, Brinquedos e Brincadeiras Infantis e Vestuário e Acessórios. Para abarcar o critério diatópico-cinético, para cada questão analisada no léxico, elaboramos duas cartas na tese: a primeira do tipo A: diatópica geral, e a segunda do tipo B: diatópica-cinética; nessa última modalidade cartográfica são dispostas separadamente as escolhas responsivas dos informantes topoestáticos dos topodinâmicos.

A seguir apresentamos nuances nos dois níveis da língua trabalhados: fonéticofonológico e semântico-lexical. No nível fonético, para este artigo, selecionamos a variação do rótico em coda medial. No lexical, optamos por demonstrar as formas encontradas para o inseto cambito/libélula, em que cavalo/cavalinho (de/do capeta, cão, jиdeu) demarcam importante isoléxica, também evidenciada em outras análises lexicais da tese. A presente área, ao sudeste do Tocantins, limítrofe à Bahia, intitula-se, pela autora, de área dialetal A: Tocantins Antigo (SILVA, 2018) e converge com o espaço designado por Nascentes (1953) como Falar Baiano.

\section{Análises fonéticas e lexicais: nuances do português falado no Tocantins-TO}

\subsection{Variável fonético-fonológica: o róticos em coda medial}

Pesquisadores tem se debruçado sobre a variação do fonema /R/ no conjunto dos falares brasileiros, buscando uma delimitação de áreas dialetais para o fato em questão, o que tem demonstrado, por vezes, uma mudança em curso do fonema em décadas. Exemplarmente, Callou (1987), com dados da década de 70, verifica que a fricativa velar, naquele recorte, caracterizava a cidade do Rio de Janeiro. Duas décadas depois, a autora atesta um processo de mudança, cuja fricativa preterida pelos falantes cariocas passou a ser representado pela glotal (CALLOU; LEITE; MORAES, 2002), mudança essa, segundo os pesquisadores, provocado possivelmente pelo processo de debucalização, quando um segmento perde seu ponto de articulação no trato oral. 
Observamos também as pesquisas sobre o retroflexo, em que estudos de outrora mostravam que esse tipo de $/ \mathrm{R} /$ era encontrado em regiões interioranas, como aponta Amaral, em localidades paulistas (AMARAL, 1920). Posteriormente, e a partir da análise, principalmente dos atlas linguísticos brasileiros, Brandão (2007) verifica que abrangência do retroflexo perpassa fronteiras nortistas e nordestinas.

Aguilera (2012) indica que o retroflexo tem migrado consideravelmente para outras regiões brasileiras devido à segmentos de ordem diatópica e social. Para ela, o avanço desse tipo de /R/ está vinculado aos grupos jovens e urbanos, denotando que esse tipo de rótico está perdendo seu status de estigmatizado como variante pertencente a grupos "caipiras".

Não obstante a presença do retroflexo em limites norte e nordestinas, na região Norte, a variante mais utilizada é a glotal, como pode ser evidenciado pelo estudo de Costa (2015), com os dados do ALiB coletados no Amazonas, no Amapá, no Pará, no Acre, em Rondônia e no Tocantins. Nesses dados, a aspirada ou glotal representa $82 \%$ das ocorrências, seguida por $11 \%$ de apagamento e 7\% de tepe alveolar (COSTA, 2015, p. 54). Apesar da predominância da glotal nos dados da autora, segundo ela, o Tocantins, dos cinco estados analisados, apresenta maior índice de tepes se comparados aos outros estados nortistas (COSTA, 2015, p. 67).

Diante do exposto, para verificarmos a variante rótica preterida no espaço tocantinense, utilizamos 949 registros obtidos por meio dos vocábulos do Questionário Fonético-Fonológico (QFF): 10 - torneira; 18 - gordura; 23 - fervendo; 34 borboleta; 43 - tarde; 46 - catorze; 69 - certo; 72 - perdão; 94 - perfume e 98 perdida ${ }^{6}$, cujo número de ocorrências e percentuais por variantes estão descritos no Quadro 2.

\footnotetext{
${ }^{6}$ Para verificar o quadro que apresenta os índices de ocorrências por variantes de /R/ em coda interna distribuídas pelos itens lexicais investigados, vide Silva (2018, p.116). 
Quadro 2: Índice geral de ocorrências e percentuais para o /R/ em coda medial.

\begin{tabular}{|c|c|c|}
\hline Variante & N. $^{0}$ de ocorrências & $\%$ \\
\hline [h] Fricativa glotal & 650 & $68,5 \%$ \\
\hline [x] Fricativa velar & 110 & $11,6 \%$ \\
\hline [r] Retroflexo & 88 & $9,3 \%$ \\
\hline Apagamentos & 60 & $6,3 \%$ \\
\hline [r] Tepe & 39 & $4,1 \%$ \\
\hline \multirow[t]{2}{*}{ [r] Vibrante múltipla } & 2 & $0,2 \%$ \\
\hline & 949 & \\
\hline
\end{tabular}

Fonte: ALiTTETO (SILVA, 2018).

O Tocantins opta pela fricativa glotal, a exemplo do que ocorre nos dados de Costa (2015). Por outro lado, embora a presença da glotal seja apontada em 68,5\% dos casos no Tocantins, esse número ainda é menor se comparados com outros estados nortistas; o Pará, por exemplo, apresenta 87\% de uso da glotal (COSTA, 2015, p. 67), podendo evidenciar que fatores migratórios influenciaram na norma tocantinense quanto a esse uso.

Diatopicamente, a glotal encontra-se de forma equânime, pelo menos, em 11 localidades. Apenas em Araguatins, divisa com o Pará, essa variante ocorre em menor proporção, sendo a fricativa velar a mais incidente nessa cidade, quando esperávamos que, na divisa com o estado paraense, os índices de glotais seriam maiores do que os de velares, como evidenciado na Carta F47-B. 
Figura 1: Carta F47-B - distribuição das variantes para /R/ em coda medial entre os dois grupos de informantes. ${ }^{7}$
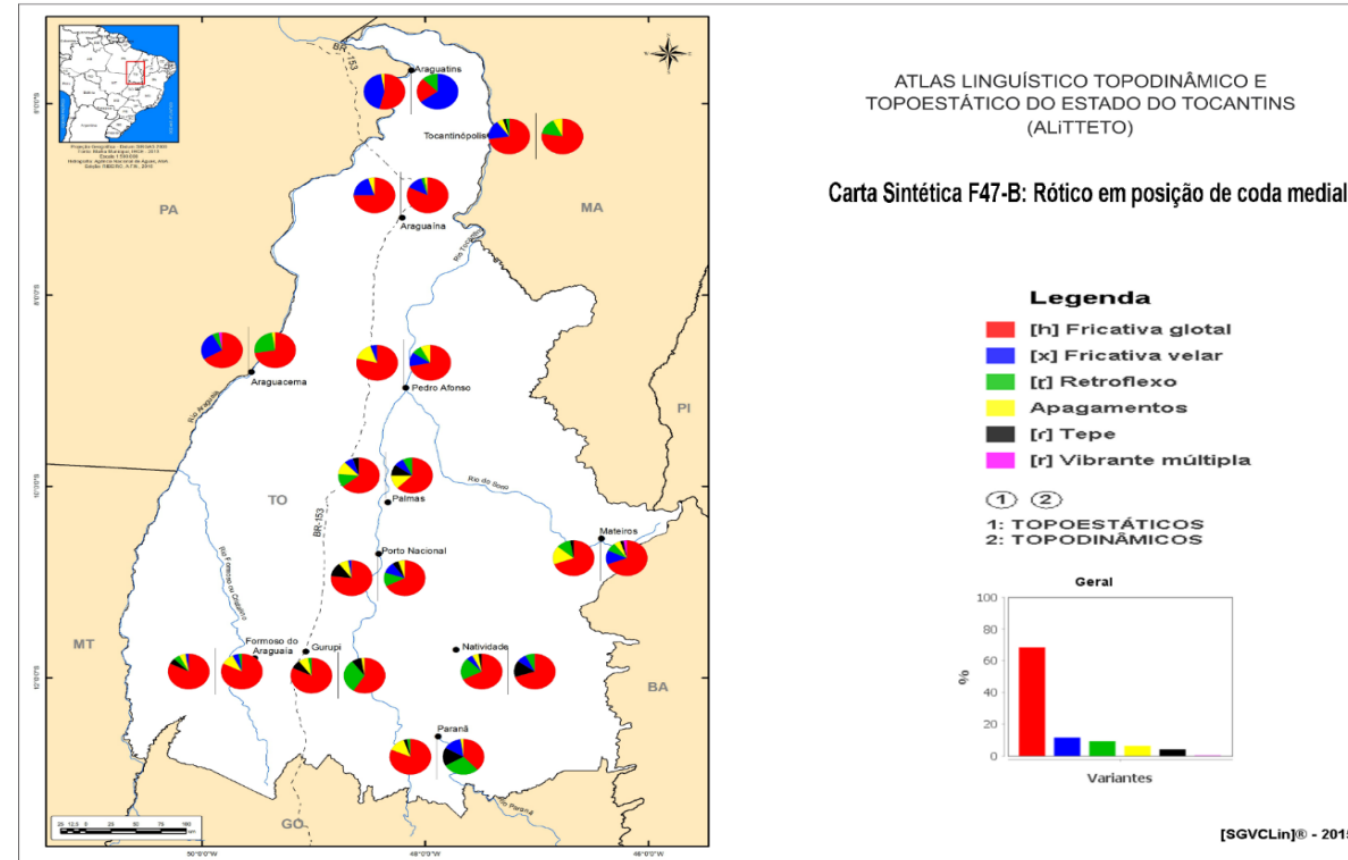

Fonte: ALiTTETO (SILVA, 2018).

Os demais róticos ocorrem em menores percentuais. A velar, segunda variante em termos numéricos, $11 \%$, ocorre, à exceção de Gurupi, em todas as localidades. Em Araguatins, extremo norte tocantinense, suplanta a glotal, como já apontado, e também ocorre em Araguaína, embora não como hegemônica.

O retroflexo registra-se em apenas $9,3 \%$ dos casos e estão concentrados em Paranã, Gurupi e Araguacema, o que, apesar da baixa incidência em termos gerais, corrobora a pesquisa de Brandão (2007) sobre a propagação desse rótico para regiões nortistas.

Há ainda casos de apagamentos em coda interna, principalmente no item catorze, sendo Palmas a responsável pelo maior percentual de neutralização. Segundo Hora e Monaretto (2003) e Costa (2015), o processo de apagamento dá-se diante de consoante fricativa, levando à anulação do rótico pelo contato com as consoantes com o mesmo modo de articulação.

O quinto lugar em termos produtivos é ocupado pela vibrante alveolar simples, ou tepe, amplamente encontrada em regiões sulista (MONARETTO, 2002), e que em

\footnotetext{
${ }^{7}$ No cartograma, as esferas à esquerda representam os informantes locais, topoestáticos; nas esferas localizadas à direita estão inseridas as respostas dos informantes migrantes, topodinâmicos.

Revista Moara, n. 55, jan-jul 2020 ISSN: 0104-0944 
nosso recorte ocorre justamente nas localidades onde há mais fluxo migratório procedente da região Centro-Sul, nas localidades de Gurupi, Formoso do Araguaia, Palmas, Natividade e Paranã, demonstrando que esse tipo de variante é trazida pelos informantes topodinâmicos, o que veremos mais adiante.

Por fim, em menor escala, há a vibrante múltipla apenas em Mateiros e em Araguacema, não sendo possível estabelecer distinção diatópico-social alguma para expressar a ocorrência dessa variante nas referidas cidades. Não há registros dessa vibrante nos estados nortistas analisados por Costa (2015).

A distribuição das variantes por variáveis sociais, idade, sexo e mobilidade, evidenciada no Gráfico 1, mostra que em todos os segmentos predomina a fricativa glotal.

Gráfico 1: Distribuição das variantes de /R/ por variáveis extralinguísticas - coda interna.

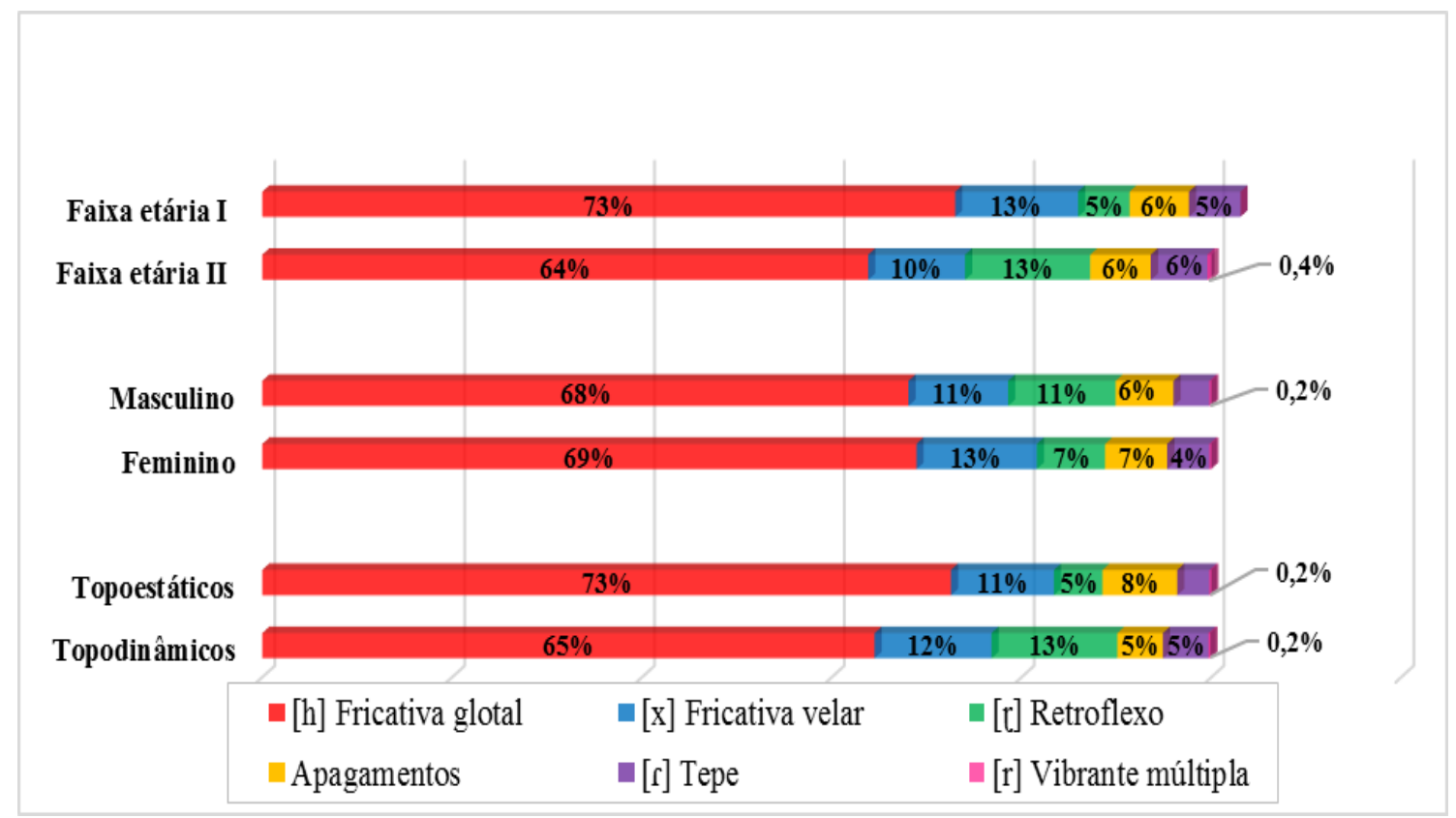

Fonte: ALiTTETO (SILVA, 2018).

Os informantes jovens e os naturais da localidade em estudo são os que mais fazem uso da fricativa glotal e os que menos utilizam o retroflexo, tendência também verificada nos dados de Costa (2015, p. 69). A fricativa velar foi mais recorrente entre os jovens e os migrantes. A faixa etária II, constituída pelos informantes com idades entre 50 a 65 anos, e os migrantes são os que apresentam maiores índices para o 
retroflexo (13\%). O tepe, com baixa incidência (entre $0,2 \%$ e $6 \%$ ), foi registrado entre os informantes da faixa etária II e os topodinâmicos.

Quanto à variável sexo, a velar foi mais frequente na fala feminina e a retroflexa na fala masculina. Os apagamentos, assim como atestado em Costa (2015, p.71), apresentam maiores índices na fala das mulheres. No entanto, em relação à utilização do tepe, enquanto em Costa (2015) se verifica maior recorrência no falar dos homens, em nosso corpus, aparece com mais frequência no núcleo feminino.

Em suma, a norma fonética do Tocantins, quanto ao uso do rótico, vincula-se à região Norte, como se nota em todos os segmentos sociais analisados. No entanto, apesar de seu predomínio no espaço tocantinense, notamos que o número de ocorrências da fricativa glotal ainda é menor se comparados aos outros estados da região nortista (COSTA, 2015). Tal fato pode indicar que os processos sociais tocantinenses, tais como formação do espaço, presença de migrantes mais expressiva do que em outras regiões, constitui-se distinto dos demais estados do Norte.

\subsection{Variável semântico-lexical: cambito e libélula}

Para tratar o nível lexical selecionamos as formas decorrentes do questionamento 065 - Como se chama o inseto de corpo comprido e fino, com quatro asas bem transparentes, que voa e bate a parte traseira na água?, cuja análise tem demostrado caráter polissêmico quando da emissão respostas, a exemplo do trabalho de Aguilera (2010b), o que pode indicar as crenças populares sobre o inseto em questão. Outro fator importante nesse recorte é a evidenciação de uma área dialetal na parte sudeste do Tocantins em relação a algumas variantes coletadas para essa pergunta.

Em relação aos nomes fornecidos ao inseto, seus traços naturais fazem com que o falante atribua diferentes formas de nomeá-lo, sobretudo tendo em vista sua forma física e seus hábitos ${ }^{8}$ (LENKO; PAPAVERO, 1996; AGUILERA, 2010b).

Salvo as 24 abstenções, ao todo, coletamos 88 respostas, distribuídas em 15 formas distintas. A maioria delas apresenta baixo índice de produtividade, citadas por um ou dois informantes, mas, apesar da baixa produtividade de algumas formas, essas ocorrências demarcam aspectos históricos e sociais nas regiões de pesquisa.

\footnotetext{
${ }^{8}$ As crenças populares que circundam o inseto são descritas por Lenko e Papavero: Insetos no Folclore (1996, p. 101-102). 
Além disso, não raro, os informantes citaram formas lexicais que remetem a outros insetos, por isso, para validar essas respostas, usamos como critério as descrições fornecidas pelos próprios informantes no momento da elocução. O Quadro 3 mostra as variantes, o número de ocorrências e os percentuais de cada uma delas.

Quadro 3: Designações para o inseto de corpo comprido e fino, com quatro asas transparentes, que voa e bate a parte traseira na água, e respectivos números de ocorrências e percentuais

\begin{tabular}{|c|c|c|c|c|c|}
\hline Variante & $\begin{array}{c}\mathrm{N}^{\circ}{ }^{\mathbf{d}} \mathrm{de} \\
\text { ocorrências }\end{array}$ & $\%$ & Variante & $\begin{array}{c}\text { N. }{ }^{\mathbf{o}} \text { de } \\
\text { ocorrências }\end{array}$ & $\%$ \\
\hline Cambito & 36 & $41,0 \%$ & Louva-deus & 2 & $2,3 \%$ \\
\hline Libélula & 20 & $22,7 \%$ & Grilo-de-rabo & 1 & $1,1 \%$ \\
\hline Lava (bunda, cu, cuida) & 8 & $9,1 \%$ & Esperança & 1 & $1,1 \%$ \\
\hline $\begin{array}{l}\text { Cavalo/cavalinho (de/do } \\
\text { capeta, cão, judeu) }\end{array}$ & 7 & $8,0 \%$ & Cabra-cega & 1 & $1,1 \%$ \\
\hline Helicóptero & 3 & $3,4 \%$ & Mané-mago & 1 & $1,1 \%$ \\
\hline Besouro & 2 & $2,3 \%$ & Canzil & 1 & $1,1 \%$ \\
\hline Palito & 2 & $2,3 \%$ & Tesoureiro & 1 & $1,1 \%$ \\
\hline Cavaleiro & 2 & $2,3 \%$ & & & \\
\hline
\end{tabular}

Fonte: ALiTTETO (SILVA, 2018).

Predomina cambito nas cidades do Tocantins e distribui-se, à exceção da área sudeste, por todo o território de pesquisa. Sua presença é mais significativa no centronorte do estado, como se verifica na Carta L8, com a distribuição diatópica dos termos mais recorrentes ${ }^{9}$.

\footnotetext{
${ }^{9}$ Optamos por não inserir no cartograma as 15 formas coletadas, com o intuito de facilitar a visualização diatópica das formas mais recorrentes.
}

Revista Moara, n. 55, jan-jul 2020 ISSN: 0104-0944 
Figura 2: Carta L8 - distribuição das variantes para cambito/libélula.

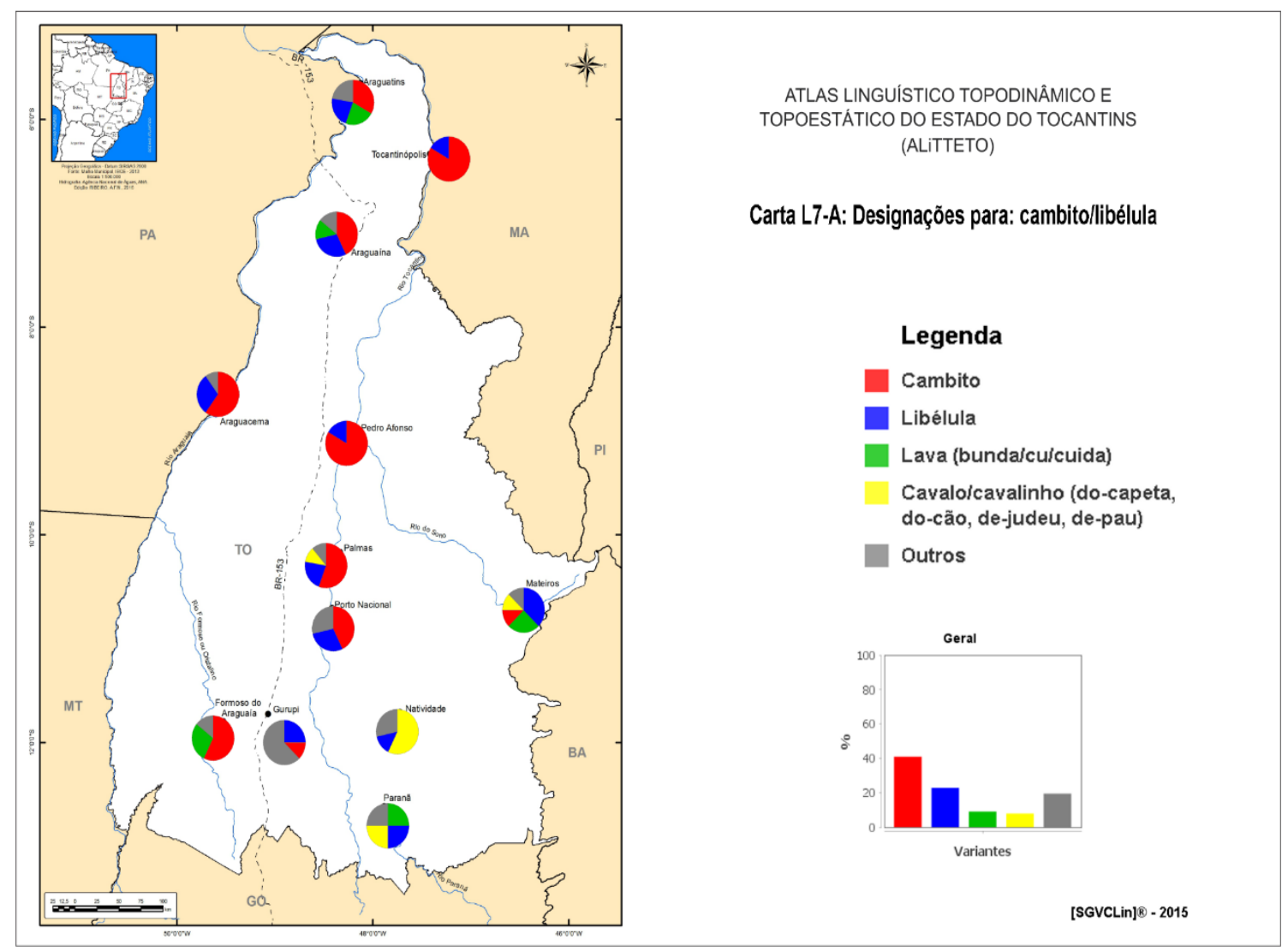

Fonte: ALiTTETO (SILVA, 2018).

Cambito é encontrado em Aulete (1986) como designativo vulgar para libélula. Em Houaiss (2009), há o indicativo de que cambito seja regionalismo nordestino, de origem obscura, com datação remontando ao século XIV.

Não há registro de cambito nas capitais do ALiB (CARDOSO et al., 2014). Entretanto aparece nos dados de Guedes (2012) mais expressivamente na região sudeste do Pará, divisa com Tocantins, muito embora a variante mais produtiva nesse estado seja jacinta. No Maranhão, segundo Ramos et al. (2012), com os dados do ALiB, cambito é registrado no sentido leste-oeste, na metade sul do estado. Em Augusto (2012), em Goiás, a referida unidade foi coletada como incidência única em Aruanã (oeste de Goiás, divisa com o Mato Grosso). Os fatos apontados nos levam a supor que, ao contrário dos dicionaristas, cambito não se encontra restrita ao Nordeste, mas irradia no sentido Norte, descendo pelo Tocantins e chegando com pouca incidência em Goiás. 
Libélula, considerada variante padrão, foi a segunda mais produtiva; com exceção de Formoso do Araguaia, foi registrada em todo o território e hegemonicamente citada pelos informantes da primeira faixa etária, com leve tendência às mulheres utilizarem essa variante. Nas capitais analisadas pelo ALiB, registra-se em todas as regiões brasileiras (AGUILERA, 2010b; CARDOSO et al., 2014).

Segundo Aulete (1986), o termo é proveniente do latim clássico libellula, talvez por alusão à libella, que significa nível/prumo, possivelmente uma menção às longas asas do animal e o movimento do voo. Segundo Aguilera, em Portugal, é conhecida como libelinha, forma utilizada no diminutivo, remetendo à delicadeza do animal (AGUILERA, 2010b).

Com oito ocorrências, temos os itens agrupados sobre o sema lava: lava-bundal lava-cu/lava-cuida. Houaiss (2009) apresenta as acepções lava-bunda e lava-cu como sinônimos para libélula, porém cita que a primeira é um regionalismo sulista, enquanto a segunda relaciona-se ao estado de Sergipe. No ALiB, além das capitais sulistas, há a presença dessas variantes no Sudeste e no Centro-Oeste (AGUILERA, 2010b; CARDOSO et al, 2014).

No caso dessas variantes agrupadas sob o sema lava, o fator diatópico não foi preponderante, uma vez que foram coletadas em cinco localidades distintas, sem aparente conexão social ou histórica entre elas. Por outro lado, o eixo "mobilidade" mostrou-se produtivo, pois todos os informantes que as citaram são provenientes de deslocamentos ou de migrações.

O agrupamento cavalo/cavalinho (de/do capeta, cão, judeu, pau) apresentou baixa produtividade $(8,0 \%)$ no corpus, entretanto, evidencia-se em forma de isoléxica, uma vez que foi coletado apenas nas localidades de Mateiros, Palmas, Natividade e Paranã, as três últimas pertencem ao ciclo histórico do estado, e Mateiros localiza-se na tríplice fronteira: Bahia, Piauí e Maranhão.

A seguir, a carta demonstra a arealidade de cambito em contraste com cavalo/cavalinho (de/do capeta, cão, judeu, pau). 
Figura 3 - Carta demonstrativa de arealidade: cambito vs cavalo/cavalinho.

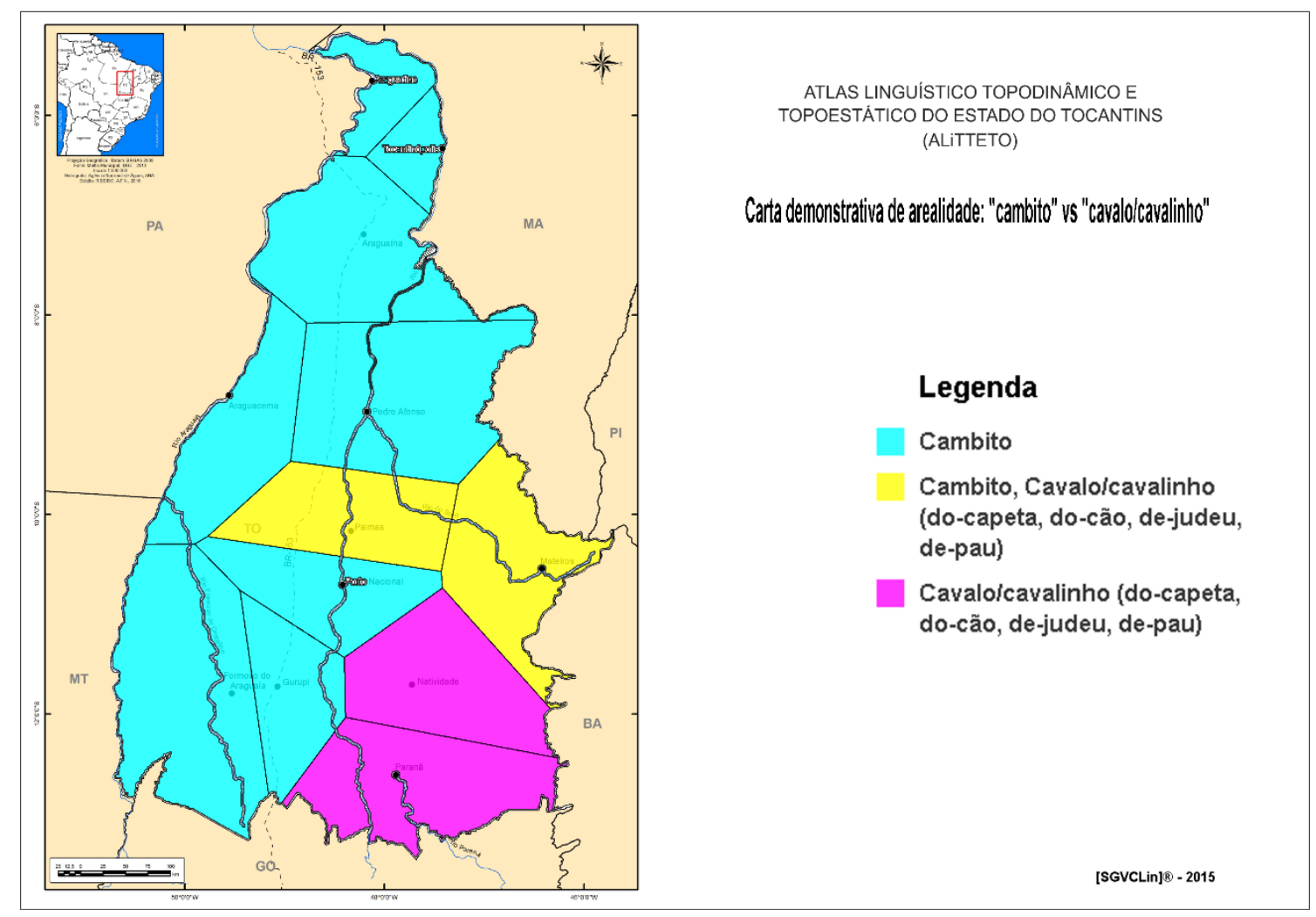

Fonte: ALiTTETO (SILVA, 2018).

A carta evidencia a divisão entre a região em que prepondera cambito, em todo o norte, descendo pela lateral esquerda e adentrando o sudoeste do Tocantins. Em posição oposta, estão as localidades em que predominam cavalo/cavalinho e seus respectivos agrupamentos, restritos ao Sudeste. Por fim, a área amarela representa o espaço em que ambas as variantes covariam, seria o ponto de contato entre cambito e cavalo/cavalinho.

Sobre a procedência das entradas cavalo/cavalinho, não há consenso entre os dicionaristas, apesar de todos apontarem que as designações são datadas no século XX. Em Houaiss (2009), cavalinho-do-diabo é marcado como regionalismo brasileiro; já cavalinho-de-judeu é fornecido como regionalismo da Bahia. Para Aulete (1986), cavalinho-de-judeu é retratado como brasileirismo do nortista.

Em Lenko e Papavero (1996), cavalinho-de-judeu é um designativo comum de Pernambuco ao Amazonas, além de ser muito conhecido em Portugal e em outros países europeus. De acordo com Rolland (1911, p. 83), tanto cavalo/cavalinho-do-cão, do 
diabo ou de judeu são nomes atribuídos em decorrência de o inseto, a partir do ciclo imaturo, até seu estágio final ser alcançado, carregar preso às costas uma casca seca, o que leva os falantes a associarem a casca retorcida à semelhança com entidade demoníaca (apud LENKO; PAPAVERO, 1996, p. 102).

Segundo Pérez (2011), cavalo ou cavalinho-do-diabo aufere-se em Portugal, tanto na Ilha dos Açores quanto no continente, o que nos faz supor que essas variantes sejam originárias de países europeus, posteriormente transportadas para o Brasil. As atividades de extração do ouro em Natividade e Paranã, nos séculos anteriores, atraíram levas de portugueses, o que parece justificar a presença da variante na fala local. Por seu turno, Aguilera (2010b) destaca que caballo ou caballito del diablo são variantes utilizadas também em partes da América do Norte: Novo México e Colorado.

Helicóptero, nosso quarto item, ocorreu apenas em Formoso do Araguaia e Gurupi, localidades próximas da BR-153. As três ocorrências foram obtidas junto aos informantes jovens, dois deles nascidos nas cidades de pesquisa e um topodinâmico. Lenko e Papavero (1996, p. 102) asseveram o caráter jovial do emprego do termo, pois, segundo eles, é muito utilizado por crianças.

$\mathrm{O}$ registro dessa variante também foi realizado pelo ALiB em capitais muito distintas: Florianópolis, Curitiba, São Paulo, Campo Grande, Goiânia, Natal e Rio Branco, o que dificulta encontrar a origem do item lexical. Houaiss (2009) apresenta helicóptero apenas como regionalismo brasileiro, sem especificar a possível região de origem dessa designação. Os próximos volumes do ALiB, contendo os dados das localidades do interior, possivelmente, elucidarão essa questão.

Quatro variantes obtiveram duas respostas cada, ou seja, 2,3\% do total: besouro, palito, cavaleiro e louva-deus, sendo as três primeiras citadas em Gurupi, cidade às margens da rodovia Transbrasiliana (BR-153). Louva-deus ocorreu apenas em Araguatins, extremo Norte do estado; validamos as duas respostas dos informantes idosos em relação a esse último item, dado o caráter diatópico centralizado das respostas e as descrições dos informantes. Nenhum dos termos encontra-se lexicalizado nos dicionários aqui trabalhados como sinônimo para o inseto em questão.

No ALiB, o item besouro realizou-se na capital Florianópolis. Em nossos dados, foi proferido pelo informante jovem topodinâmico, em Gurupi, localidade que recebeu e 
tem recebido muitas frentes sulistas em seu território, o que pode explicar a presença dessa variante.

Seis termos - grilo-de-rabo, esperança, cabra-cega, mané-mago, canzil e tesoureiro - ocorreram apenas uma vez e, do ponto de vista diatópico, essas variantes esparsas estão em localidades mais recentes e com grande fluxo migratório. De todas as lexias, apenas mané-mago é descrita no ALiB, em Recife. Cabra-cega encontra-se em Lenko e Papavero (1996, p. 102) como regionalismo cearense.

As variáveis sociais apresentadas no Gráfico 2 demonstram algumas peculiaridades, das quais podemos destacar a utilização de cambito mais incidente na faixa etária II, assim como a utilização das formas cavalo/cavalinho. Por seu turno, a variante padrão libélula foi extremamente recorrente nos mais jovens; nesse núcleo também se encontram mais citações para as "demais variantes", tais como: besouro, palito, cavaleiro, louva-deus, grilo-de-rabo, esperança, cabra-cega, mané-mago, canzil e tesoureiro.

Gráfico 2 - Distribuição percentual por variáveis extralinguísticas (QSL 065)

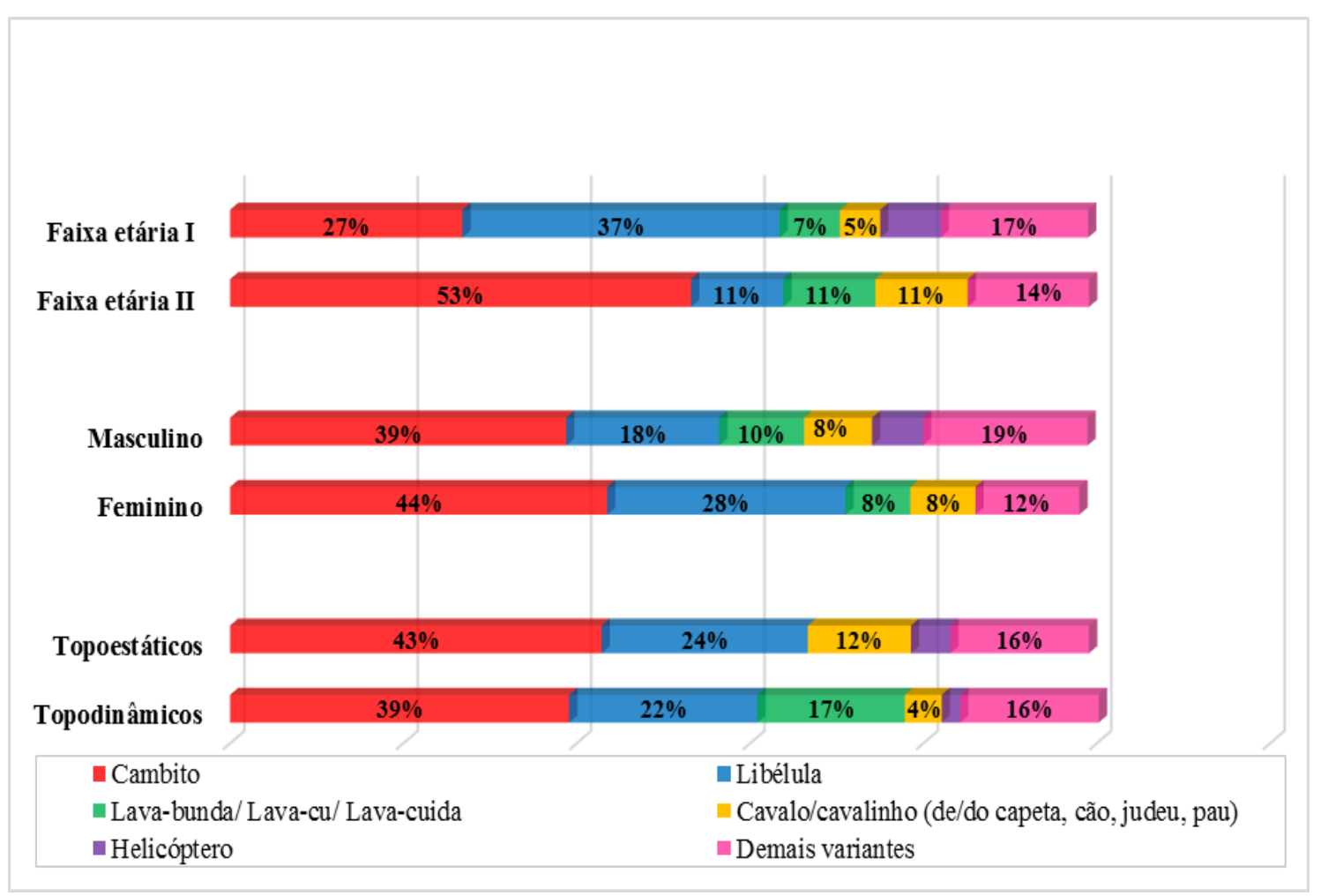

Fonte: ALiTTETO (SILVA, 2018). 
O núcleo masculino apresentou significativo índice de variantes hápax, agrupadas em "demais variantes”. As mulheres são responsáveis pelos maiores índices de cambito e libélula.

Os agrupamentos cavalo/cavalinho ocorreram predominantemente na fala dos informantes autóctones, podendo evidenciar tratar-se de variantes locais trazidas ainda no período de colonização do território, pelo núcleo português, por exemplo. Por outro lado, as designações sob o prefixo lava estão mais presentes nos informantes topodinâmicos.

Em síntese, apesar do caráter polissémico das respostas, sobre a Questão 065 do QSL, notamos a presença de isoléxica demarcada pelas formas cavalo/cavalinho (de/do capeta, cão, judeu, pau) na área Sudeste do território de pesquisa, Tocantins Antigo, região de mineração, próxima da divisa com a Bahia, resultado que também foi apontado em outras análises lexicais presentes na tese, como evidenciado por Silva (2018) quando estabelece duas grandes áreas dialetais para o Tocantins:

\footnotetext{
O espaço "A" estabelece-se no Sudeste, região mais antiga do território, que abrigou os primeiros migrantes para o trabalho nas minas auríferas. Sua composição remonta ao século XVII que tem como centro irradiador duas localidades: Natividade e Paranã. A depender da variante em análise, essa área expande-se para localidades circunvizinhas: Porto Nacional, Palmas e Mateiros, abrangendo todo o Sudeste e parte da Zona Central. Predominam nesse território semelhanças dialetais com o Nordeste brasileiro e tendência lexical a variantes mais rurais, fato que se dá pelo menor contato com as principais vias de comunicação, a rodovia Transbrasiliana, por exemplo.

Em contrapartida, a área "B" reúne as demais cidades pesquisadas, situadas nas partes Sudoeste, Centro e Norte. São de colonização mais recente e contêm assimilação com diferentes regiões, a depender dos dados, Norte, Nordeste e Centro-Oeste, possivelmente pela maior proximidade com a rodovia BR-153, que liga o Tocantins a outros estados. (SILVA, 2018, p. 202-203).
}

Assim, pelo menos no que subjaz à região sudeste tocantinense, espaço mais antigo de formação, há maior identificação com a norma baiana/nordestina. No restante do estado, área "B" há evidencias de covariação dialetal trazidas pelos migrandes das demais regiões braileiras. 


\section{Considerações finais}

O presente trabalho teve o intuito de apresentar aspectos do português falado no Tocantins, a partir do corpus coletado para o "Atlas Linguístico Topodinâmico e Topoestático do Estado do Tocantins (ALiTTETO)", desenvolvido como tese de doutorado, vinculado à Universidade Estadual de Londrina.

Sobre a variação do rótico em coda interna, predomina no Tocantins a variante glotal, tal como nas regiões Norte e Nordeste. Nota-se que a presença dos demais tipos de /R/ está ligada a grupos extralocalidades. Ressaltamos também que, apesar do predomínio da glotal, com distribuição regular, estatisticamente, o percentual dessa variante ainda é menor, se comparado a outros trabalhos dialetais da região Norte do país, o que leva ao entendimento que os processos de formação do espaço tocantinense, assim como as levas migratórias, são importantes no que subjaz a presença do rótico no estado.

Em relação ao léxico, as análises das variantes para o QSL 065 cambito/libélula, apesar do predomínio das duas formas entre os informantes, a presença dos agrupamentos cavalo/cavalinho (de/do capeta, cão, judeu, pau) traduz a área dialetal descrita por Silva (2018) e intitulada Tocantins Antigo, com identificação lexical com o Nordeste brasileiro, sobretudo referente à Área do Falar Baiano. 


\section{REFERÊNCIAS}

AGUILERA, Vanderci de Andrade. De onde vieram e por onde andam as nossas libélulas e jacintas? Um estudo da etimologia popular com base em dados do Atlas Linguístico do Brasil (ALiB). Estudos Linguísticos e Literários, Salvador, n. 41, p. 291$309,2010 b$.

AGUILERA, Vanderci de Andrade. O /R/ caipira está ganhando status? Papéis: Revista do Programa de Pós-Graduação em Estudos de Linguagens. Universidade Federal de Mato Grosso do Sul. Campo Grande-MS, 2012a.

ALTENHOFEN, Cléo Vilson. Migrações e contatos linguísticos na perspectiva da Geolinguística Pluridimensional e Contatual. Revista de Letras Norteamentos. Estudos Linguísticos, Sinop, v. 6, n. 12, p. 31-52, jul./dez. 2013. Disponível em: <http://sinop.unemat.br/projetos/revista/index.php/norteamentos/article/view/1216>. Acesso em agosto de 2016.

ALTENHOFEN, Cléo Vilson; THUN, Harald. As migrações e os contatos linguísticos na Geografia Linguística do Sul do Brasil e Bacia do Prata. In: AGUILERA, Vanderci de Andrade; ROMANO, Valter Pereira (Orgs.). A geolinguística no Brasil: caminhos percorridos, horizontes alcançados. Londrina: Eduel, 2016, p. 371-392.

AMARAL, Amadeu. $O$ dialeto caipira. 3. ed. São Paulo: HUCITEC/Secretaria da Cultura/Ciência e Tecnologia, 1976 [1920].

AUGUSTO, Vera Lúcia dias dos Santos. Atlas semântico-lexical do estado de Goiás. Tese (Doutorado) - Programa de Pós-Graduação em Semiótica e Linguística Geral. Universidade de São Paulo, 2012.

AULETE, Caldas. Dicionário contemporâneo da língua portuguesa. Rio de Janeiro: Delta, 1986.

BRANDÃO, Sílvia Figueiredo. Nas trilhas do -R retroflexo. SIGNUM: Estudos da Linguagem. $\mathrm{n}^{\mathrm{o}}$ 10/2 Londrina, 2007, p. 265-283. Disponível em: 
http://www.uel.br/revistas/uel/index.php/signum/article/viewFile/4448/5073. Acesso em 01 agost. 2020.

CALLOU, Dinah. Variação e distribuição da vibrante na fala urbana culta do Rio de Janeiro. Tese (Doutorado em Linguística). Universidade Federal do Rio de Janeiro, Rio de Janeiro, 1987.

CALLOU, Dinah; LEITE, Yonne; MORAES, João. Variação e diferenciação dialetal: a pronúncia do /R/ no português do Brasil. In: KOCH, Ingedore G. Villaça (Org.). Gramática do Português Falado. 2. ed. Campinas, S.P.: Editora da Unicamp, 2002, p. 463- 489.

CARDOSO, Suzana Alice Marcelino et al. Atlas Linguístico do Brasil: cartas linguísticas 1. Londrina: Eduel, 2014.

COMITÊ NACIONAL DO PROJETO ALiB. Atlas Lingüístico do Brasil: questionários. Londrina: Eduel, 2001.

COSTA, Fernanda Analena Ferreira Borges da. Variação do $/ R /$ em coda silábica interna no Norte do Brasil: um estudo geossociolinguístico. Dissertação (Mestrado) Universidade Federal do Pará, Instituto de Letras e Comunicação, Belém, 2015.

CUBA, Marigilda Antônio. Atlas Linguístico Topodinâmico do Território Incaracterístico. Tese (Doutorado em Estudos da Linguagem). Universidade Estadual de Londrina, Londrina, 2015.

CUNHA, José Marcos Pinto da; BAENINGER, Rosana (Coords.). Redistribuição da população e meio ambiente: São Paulo e Centro Oeste. Sistematização das Informações Censitárias sobre Migração - Estado de Tocantins. Campinas: Unicamp, Núcleo de Estudos de População, 2000.

FERREIRA, Carlota; MOTA, Jacyra, FREITAS; Judith, ANDRADE, Nadja; CARDOSO, Suzana; ROLLEMBERG, Vera; ROSSI, Nelson. Atlas Lingüístico de Sergipe. Salvador: Universidade Federal da Bahia/Fundação Estadual de Cultura de Sergipe, 1987. 
FIGUEIREDO, Carla Regina de Souza. Topodinâmica do português gaúcho em áreas de contato intervarietal do Mato Grosso. Tese (Doutorado em Letras). Universidade Federal do Rio Grande do Sul, Rio Grande do Sul, 2014.

GUEDES, Regis José da Cunha. Estudo geossociolinguístico da variação lexical na zona rural do estado do Pará. Dissertação (Mestrado) - Programa de Pós-Graduação em Letras do Instituto de Letras e Comunicação. Universidade Federal do Pará, 2012.

HORA, Dermeval da; MONARETTO, Valéria. Enfraquecimento e apagamento dos róticos. In: HORA, Dermeval da; COLLISCHONN, Gisela (Orgs.). Teoria linguística: fonologia e outros temas. João Pessoa: EDUFPB, 2003.

HOUAISS, Antônio. Dicionário Houaiss eletrônico. Instituto Antônio Houaiss. Objetiva, 2009.

LABOV, William. Padrões Sociolinguísticos. São Paulo: Parábola, 2008 [1972].

LENKO, Karol; PAPAVERO, Nelson. Insetos no folclore. Conselho Estadual de Artes e Ciências Humanas, São Paulo, 1996.

MONARETTO, Valéria. A vibrante pós-vocálica em Porto Alegre. In: BISOL, Leda; BRESCANCINI, Cláudia. (Orgs.) Fonologia e variação: recortes do português brasileiro. Porto Alegre: EDIPUCRS, 2002, p. 253-268.

NASCENTES, Antenor. O linguajar carioca. Rio de Janeiro: Organização Simões, 1953.

PÉREZ, Álvarez; AFONSO, Xosé. A joaninha era de Nossa Senhora: designações açorianas no campo lexical da fauna. O Faial e a Periferia Açoriana nos séculos XV a XX. Actas do V Colóquio. Faial: Núcleo Cultural da Horta, 2011, p. 401-423.

RAMOS, Conceição de Maria de Araujo; BEZERRA, José de Ribamar Mendes; ROCHA, Maria de Fátima Sopas; REIS, Mírian Rodrigues. No céu do Maranhão, cruzam-se catirinas, tingas e pragas: um estudo semântico-lexical da fauna maranhense. In: MOTA, Jacyra Andrade; CARDOSO, Suzana Alice Marcelino; PAIM, Marcela Moura Torres (Orgs.). Documentos 3. Projeto Atlas Linguístico do Brasil. Vozes do X 
WORKALiB: amostras do português brasileiro. Salvador: Vento Leste, 2012, p. 263280.

ROLAND, Eugène. Faune populaire de la France. Tomo XIII. Les insectes. Paris, 1911.

ROSSI, Nelson; FERREIRA, Carlota; ISENSEE, Dinah. Atlas Prévio dos Falares Baianos. Rio de Janeiro: Ministério de Educação e Cultura; Instituto Nacional do Livro, 1963.

SILVA, Greize Alves da. Atlas Linguístico Topodinâmico e Topoestático do Estado do Tocantins (ALiTTETO). 2018. 2v. Tese (Doutorado em Estudos da Linguagem). Universidade Estadual de Londrina, Londrina, 2018.

SILVA, Greize Alves da; BORGES, Patrícia Andrea. Presença vs ausência de traços de ruralidade no léxico tocantinense. Revista do Instituto de Estudos Brasileiros, v. 0i, p. 83-105, 2019.

THUN, Harald. La geolingüística como lingüística variacional general (con ejemplos del Atlas lingüístico Diatópico y Diastrático del Uruguay). In: INTERNATIONAL CONGRESS OF ROMANCE LINGUISTICS AND PHILOLOGY (21.: 1995: Palermo). Atti del XXI Congresso Internazionale di Linguistica e Filologia Romanza. (Orgs). Giovanni Ruffino. Tübingen: Niemeyer, 1998. v. 5, p. 701-729, incluindo resumo dos tópicos principais da seção 5, p. 787-789. 